\title{
EVIDENCE FOR SELECTIVE RELEASE OF SOMATOSTATIN-14 AND SOMATOSTATIN-28(1-12) FROM RAT HYPOTHALAMUS ${ }^{1}$
}

\author{
C. BAKHIT, ${ }^{2}$ L. KODA, R. BENOIT, ${ }^{*}$ J. H. MORRISON, AND F. E. BLOOM \\ A. V. Davis Center for Behavioral Neurobiology and *Laboratories for Neuroendocrinology, The Salk Institute, \\ La Jolla, California 92037
}

Received March 24, 1983; Revised August 5, 1983; Accepted August 19, 1983

\begin{abstract}
Cysteamine administration to rats results in a marked depletion of hypothalamic somatostatin14 (SS14) and a decrease of the potassium-evoked in vitro release of SS14 without a significant change in the content or release of somatostatin-28(1-12)-like immunoreactivity (SS28(1-12)-L1). Furthermore, cysteamine enhances the spontaneous release and markedly potentiates the potassiumevoked release of SS14 in the in vitro slice preparation. However, in vitro-administered cysteamine does not alter the spontaneous or potassium-evoked release of SS28(1-12)-LI. Immunohistochemical visualization of hypothalamic neuronal cell bodies and fibers following cysteamine administration shows a disappearance of the SS14 immunoreactive fibers and cell bodies with no apparent change in the SS28(1-12) immunoreactive fibers and cell bodies. These data suggest that, in rat hypothalamus, selective release of SS14 and SS28(1-12) can occur. The results are discussed in relation to possible sites of storage and release of the somatostatin-related peptides from synaptic nerve terminals.
\end{abstract}

Recent investigations aimed at identifying the prosomatostatin precursors have resulted in the discovery of two somatostatin-related peptides: somatostatin-28 (SS28), which contains the original tetradecapeptide somatostatin-14, and the other newly discovered dodecapeptide somatostatin-28(1-12), which corresponds to the $\mathrm{NH}_{2}$-terminal portion of SS28. These two fragments and the original tetradecapeptide were found to be widely distributed throughout the central nervous system and gastrointestinal tract (Hokfelt et al., 1974; Brownstein et al., 1975; Kobayashi et al., 1977; Morrison et al., 1982, 1983; Benoit et al., 1982a, b, c). They are present in cell bodies and nerve terminals (Hokfelt et al., 1974; Epelbaum et al., 1977; Kewley et al., 1981; Morrison et al., 1983) and can be released in vitro upon depolarization in a calcium-dependent manner (Iversen et al., 1978; Gamse et al., 1980; Kewley et al., 1981; Bakhit et al., 1983a). Furthermore, SS28 or SS14 can either excite or inhibit neocortical and hippocampal neurons (Dodd and Kelly, 1978; Olpe et al., 1980; Pittman and Siggins, 1981) and

\footnotetext{
${ }^{1}$ We thank Dr. Nicholas Ling for providing the peptides, Nancy Callahan for typing the manuscript, and Barbara Alford for technical assistance. Research was supported by NIAAA Grants AA 07273 and AA03504, by National Heart, Lung and Blood Institute Grant HL 25457, and by a Medical Research Council of Canada fellowship to R. B.

${ }^{2}$ To whom correspondence should be addressed, at The Salk Institute, P. O. Box 85800, San Diego, CA 92138.
}

have high affinity binding sites (Reubi et al., 1981; Srikant and Patel, 1981; Tapia-Arancibia et al., 1981), and SS14 has been shown to regulate the release of other neurotransmitters in the brain (Gothert, 1980; Tanaka and Tsujimoto, 1981; Chesselet and Reisine, 1983).

In an effort to investigate how the somatostatin-related peptides are stored and released, we have examined the in vitro release of SS14 and SS28(1-12)-LI from rat hypothalamic slices following in vivo or in vitro treatment with cysteamine, a drug previously shown to have specific depleting effects on SS14 (Szabo and Reichlin, 1981; Palkovits et al., 1982; Sagar et al., 1982; Bakhit et al., 1983b; Brown et al., 1983) but which does not influence the tissue stores of SS28(1-12)-LI (Bakhit et al., 1983b). In addition, we have examined rat hypothalamic tissue labeled with antisera directed against these somatostatin-related peptides in normal and cysteaminepretreated rats to determine the sites which retain immunoreactivity after cysteamine exposure. Our results indicate that, in rat hypothalamus, selective release of SS14 and SS28(1-12) may occur.

\section{Materials and Methods}

Male Sprague-Dawley rats weighing 180 to $220 \mathrm{gm}$ were used. Rats were housed three per cage in a temperature-controlled $\left(24^{\circ} \mathrm{C}\right)$ room with a 12-hr light-dark cycle. Rats were given food and water ad libitum.

Groups of rats were injected subcutaneously with 
either saline or cysteamine hydrochloride $(300 \mathrm{mg} / \mathrm{kg}) 4$ $\mathrm{hr}$ before decapitation. The $\mathrm{pH}$ of the cysteamine solution was adjusted to 7.4 with $\mathrm{NaOH}$. For the release experiments, rats were decapitated and the hypothalami were rapidly dissected according to the procedure of Glowinski and Iversen (1966) and cross-cut at 250- $\mu \mathrm{m}$ intervals using a McIlwain tissue chopper. The resulting slices were washed three times with a modified Krebsbicarbonate solution containing the following: $\mathrm{NaCl}, 127$ $\mathrm{mM} ; \mathrm{KCl}, 3.83 \mathrm{mM} ; \mathrm{CaCl}_{2}, 1.7 \mathrm{mM} ; \mathrm{KH}_{2} \mathrm{PO}_{4}, 1.18 \mathrm{~mm}$; $\mathrm{MgSO}_{4}, 1.18 \mathrm{mM} ; \mathrm{NaHCO}_{3}, 20 \mathrm{mM}$; D-glucose, $2 \mathrm{gm} /$ liter; bovine serum albumin (crystalline, Miles Laboratories), $0.1 \%$; bacitracin (Sigma), $30 \mu \mathrm{g} / \mathrm{ml}$. The medium was gassed with an oxygen/carbon dioxide $(95 / 5, \mathrm{v} / \mathrm{v})$ mixture. The final $\mathrm{pH}$ was 7.4 . For stimulation with potassium, $50 \mathrm{mM} \mathrm{KCl}$ was substituted in part for $\mathrm{NaCl}$ (isomolar replacement). Hypothalamic slices from six rats suspended in Krebs-bicarbonate medium were placed in a superfusion chamber made up of a 1-inch diameter Easy Pressure Filter Holder with a $0.45-\mu \mathrm{m}$ Metrical membrane filter (Gelman Sciences). The Krebsbicarbonate buffer was passed through the chamber at a rate of $400 \mu \mathrm{l} / \mathrm{min}$ using a $5-\mathrm{ml}$ syringe mounted on a delivery apparatus. All release experiments were performed at room temperature. After an initial wash period of $10 \mathrm{~min}$, perfusate samples were collected at 2-min intervals, immediately boiled for $15 \mathrm{~min}$, and kept frozen until assayed. At the end of the experiment, the hypothalamic slices were extracted in $4 \mathrm{ml}$ of $1 \mathrm{M}$ acetic acid, boiled, homogenized, and centrifuged. The resulting supernatant was freeze-dried for radioimmunoassay using specific antisera directed against SS14 and SS28(1-12) (Benoit et al., 1982a, b). Statistical significance was determined by the Student's $t$ test.

To determine the nature of the material measured by radioimmunoassay in the perfusate, boiled fractions collected during potassium-evoked release from 12 chambers each containing five hypothalami, in the presence or absence of cysteamine, were pooled and centrifuged at $2000 \times \mathrm{g}$ at $4^{\circ} \mathrm{C}$ for $30 \mathrm{~min}$. The supernatant was lyophilized and the dry material (about $700 \mathrm{mg}$ in each case) dissolved in $13 \mathrm{ml}$ of $5 \mathrm{M}$ acetic acid and loaded onto a Sephadex G-75 column $(2.7 \times 108 \mathrm{~cm})$. The column was eluted with $5 \mathrm{~m}$ acetic acid, and 8.5-ml fractions were collected, lyophilized, and assayed by radioimmunoassay.

The immunohistochemical procedure was similar to that described previously by Morrison et al. (1983). Briefly, control and treated rats were anesthetized and perfused with $200 \mathrm{ml}$ of an ice-cold $4 \%$ depolymerized paraformaldehyde solution in phosphate buffer. Brains were postfixed for 3 to $4 \mathrm{hr}$ on ice and infiltrated with an ice-cold $18 \%$ sucrose solution. Frozen serial sections $(40 \mu \mathrm{m})$ were cut and incubated in diluted antisera as follows: s312 (1:1000), s320 (1:5000), and ss9 (1:3000). For specificity and antigen blocking of antisera, see Morrison et al. (1982). The tissues were then incubated with goat anti-rabbit IgG conjugated with fluorescein isothioncyanate (1:200, Tago). Sections were examined directly under a fluorescence microscope. The periventricular hypothalamic area and the median eminence were examined by three of the investigators without prior knowledge of either the tissue treatment or drug treat- ment. The tissue was subjectively rated as to the presence or absence of cell body and fiber labeling. These experiments were repeated on four separate occasions.

\section{Results}

Effects of in vivo cysteamine treatment on in vitro release of SS14 and SS28(1-12)LI. The release of SS14 and SS28(1-12)-LI from hypothalamic slices of rats pretreated with either saline or cysteamine was determined. Basal release of somatostatin-14 was similar in the saline- and cysteamine-pretreated groups (Table I). Potassium-evoked release produced a 4 - to 5 -fold increase in SS14 release in the control group. By contrast, only a 2fold increase over basal levels was observed with potassium-evoked release in the cysteamine-pretreated group. It should be noted that the tissue content of SS14 was markedly lower in the cysteamine-pretreated group as compared to the saline-treated controls. SS28(1-12)-LI was measured in the same perfusates. Basal release as well as tissue content of SS28(1-12)-LI was not significantly altered in the cysteamine group as compared to the saline-pretreated group (Table I). Potassium-evoked release produced a 5- to 9 -fold increase in SS28(1-12)-LI over basal levels. A similar increase of SS28(1-12)-LI release over basal levels was observed in the cysteaminepretreated as in the control group.

Effects of in vitro cysteamine treatment on in vitro release of SS14 and SS28(1-12)-LI from normal hypothalamic tissue. Cysteamine (1 mM) slightly increased SS14 release over basal levels (Fig. 1). Cysteamine also produced about a 2-fold increase in the potassium-evoked release of SS14. These effects were calcium-dependent, since removal of calcium from the media prevented the potassium stimulation as well as the potentiation of SS14 release observed with cysteamine (Bakhit et al., 1983b). The enhancing effect of cysteamine on the potassiumevoked release of SS14 was verified by column chromatography. The elution profiles on Sephadex G-75 column of perfusate samples of potassium-evoked release in the presence and absence of cysteamine (1 $\mathrm{mM})$ are similar and confirm that what is released is in fact SS14 (Fig. $2 a$ ) and that cysteamine potentiates the release of SS14 (Fig. $2 b)$. By contrast, in vitro cysteamine (1 mM) had no significant effect on either the spontaneous or the potassium-evoked release of SS28(1-12)-LI (Fig. 3). Gel permeation chromatography indicated that the dodeca-

\section{TABLE I}

Effects of cysteamine $(300 \mathrm{mg} / \mathrm{kg}$, s.c.) pretrentment on the spontaneous and potassium-evoked release of SS14 and SS28(1-12)-LI from rat hypothalamus in vitro

Values are means \pm SEM of three separate experiments. Tissue content of the peptides was determined at the end of the experiment.

\begin{tabular}{llccc}
\hline \multicolumn{1}{c}{ Peptide } & Pretreatment & Basal & $\begin{array}{c}\text { Potassium-Evoked } \\
\text { Release }\end{array}$ & $\begin{array}{c}\text { Tissue } \\
\text { Content }\end{array}$ \\
\hline \multirow{3}{*}{ SS14 } & & $f \mathrm{~mol} / 4 \mathrm{~min}$ & $f \mathrm{~mol} / 4 \mathrm{~min}$ & $\mathrm{pmol}$ \\
& Saline & $45 \pm 5$ & $217 \pm 30$ & $116 \pm 9$ \\
& Cysteamine & $46 \pm 4$ & $99 \pm 15^{a}$ & $29 \pm 5^{a}$ \\
SS28(1-12)-LI & Saline & $139 \pm 27$ & $824 \pm 149$ & $104 \pm 14$ \\
& Cysteamine & $98 \pm 10$ & $872 \pm 132$ & $108 \pm 17$ \\
\hline
\end{tabular}

${ }^{\text {a }} p<0.05$ as compared to the control saline group (Student's $t$ test). 


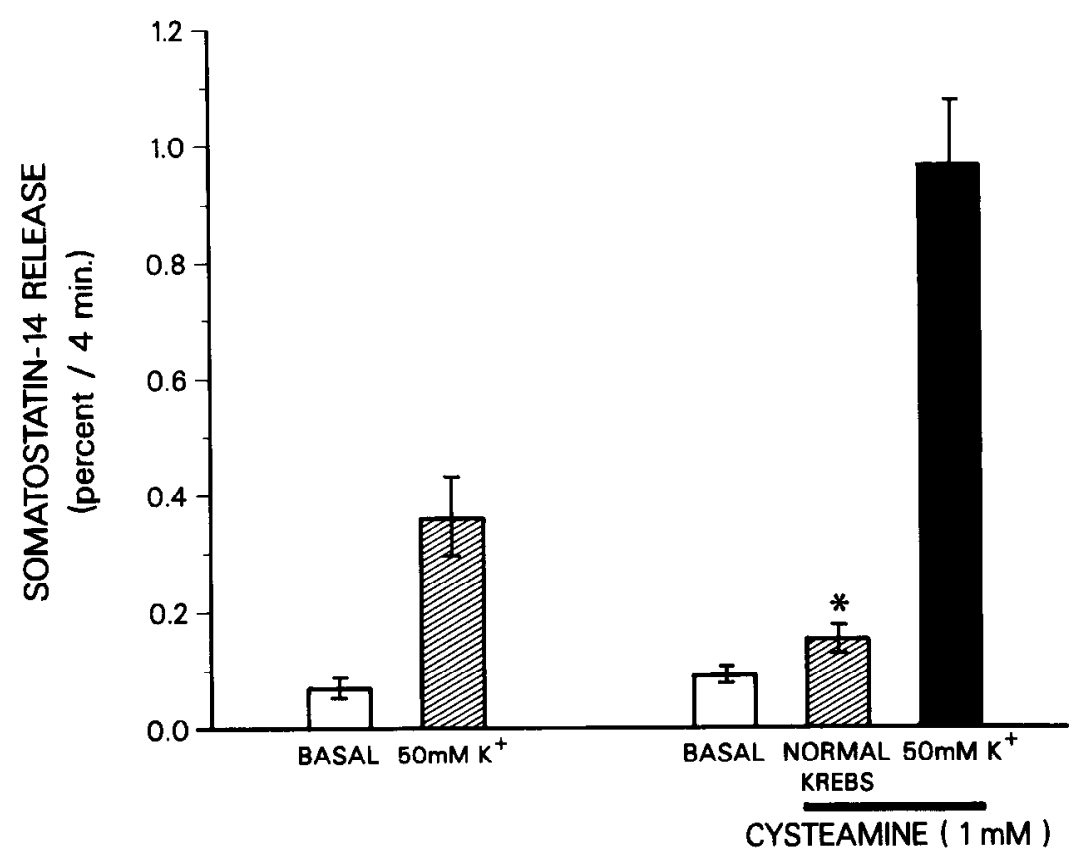

Figure 1. The effects of in vitro cysteamine $(1 \mathrm{mM})$ on the spontaneous and potassium-evoked release of SS14 from rat hypothalamic slices in vitro. Results are expressed as percentage of tissue content measured in tissue slices at the end of the experiment. Values are mean $\pm S E M$ of three separate experiments. *, significantly different from basal levels, $p<0.05$.

peptide SS28(1-12) accounts for the majority (77\%) of the SS28(1-12)-like immunoreactive material released (data not shown).

Immunohistochemistry. Hypothalamic sections taken from saline- and cysteamine-treated rats were stained with three antigen-specific rabbit antisera: $\mathrm{s} 312$ which recognizes SS14, ss9 which recognizes both $\mathrm{SS} 14$ and SS28, and s320 which recognizes SS28(1-12) (Benoit et al., 1982a, b). The staining pattern throughout the hypothalamus differed with each antiserum. s320 labeled the most fibers and $s 312$ the least. However, within the periventricular area and the median eminence the staining patterns obtained with these three antisera were qualitatively similar. Antiserum s312, which recognized SS14, labeled cell bodies and fibers in the periventricular hypothalamic area of saline-treated rats (Fig. 4a). Cysteamine treatment abolished both the perikaryal and fiber labeling of s312 (Fig. $4 b$ ). Antiserum ss9, which recognizes both SS14 and SS28, also labeled cell bodies and fibers in the periventricular hypothalamic region (Fig. 4c). Labeling with ss9 was more intense than labeling with $\mathrm{s} 312$, and many more fibers were labeled. After cysteamine treatment, cell body labeling was reduced, and practically all fiber labelling was abolished (Fig. 4d). In contrast with the other two antisera, s320 (which recognizes SS28(1-12)) produced an intense labeling of perikarya and fibers which was not reduced by cysteamine treatment (Fig. 4, $e$ and $f$ ).

Analogous observations were made in the median eminence (Fig. 5). The intense fiber labeling seen in salinetreated rats with $\mathrm{s} 312$ (recognizes SS14; Fig. $5 a$ ) and ss9 (recognizes SS14 and SS28; Fig. $5 c$ ) was markedly reduced following cysteamine treatment (Fig. 5, $b$ and $d$ ).
Again the intense labeling with s320 (recognizes SS28(112); Fig. 5e) was not apparently changed following cysteamine treatment (Fig. 5f). These observations were reproducible in four replications of the experiment.

\section{Discussion}

Cysteamine administration to rats results in both a marked decrease in the tissue content and a profound diminution of the in vitro potassium-evoked release of hypothalamic SS14. Under normal conditions, a 4- to 5fold increase over basal levels of hypothalamic SS14 release would be obtained with potassium stimulation. However, in the cysteamine-pretreated rats, potassium stimulation results in a 2 -fold increase over basal levels of SS14 released. The fact that a lower amount of SS14 is released by potassium stimulation indicates that cysteamine pretreatment affects the releasable pool of SS14. In contrast, neither the tissue content nor the release of hypothalamic SS28(1-12)-LI was significantly altered following cysteamine pretreatment. The amount of SS28 (1-12)-LI released following potassium stimulation revealed no significant difference between the control and cysteamine-pretreated groups.

Cysteamine might somehow inactivate the immunoreactivity of SS14 without affecting the release mechanisms. Such an inactivation might result in what appears to be a diminished release of SS14 as compared to release of SS28(1-12)-LI. It was, therefore, important to show that the release of one of the two peptides can be enhanced without altering that of the other. Cysteamine was used for that purpose in the in vitro experiments. Cysteamine (1 mM) enhanced the in vitro release of SS14 

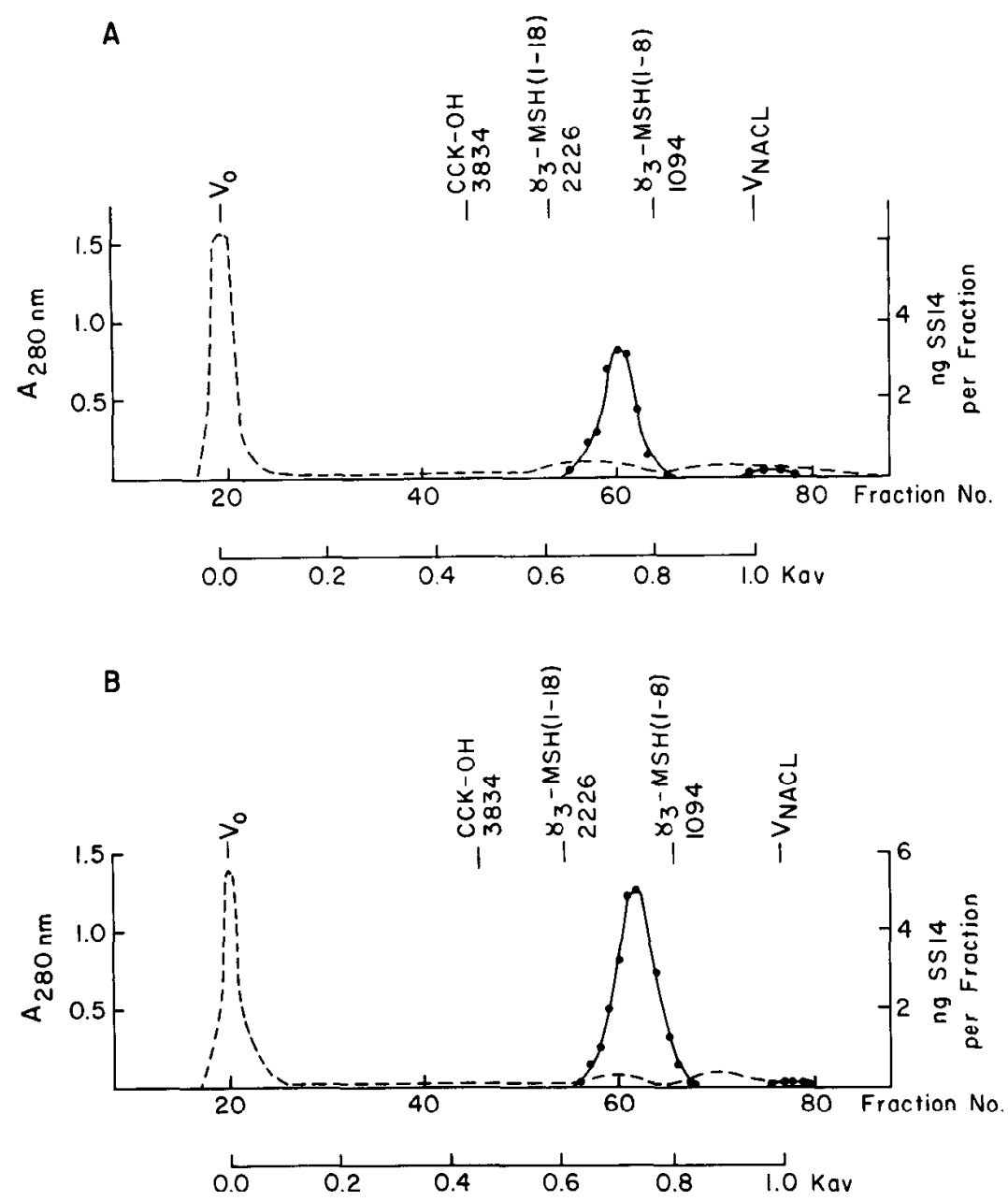

Figure 2. Elution profile of Sephadex G-75 gel permeation chromatography performed on pooled material of perfusates of rat hypothalami. $A$, Perfusates from potassium-evoked release. $B$, Perfusates from potassium-evoked release in the presence of cysteamine $(1 \mathrm{mM})$. Column bed volume, $615 \mathrm{ml}$. Elution (at $4^{\circ} \mathrm{C}$ ) with $5 \mathrm{M}$ acetic acid. Load, $700 \mathrm{mg}$. Fraction size, $8.5 \mathrm{ml}$. Flow rate, $17 \mathrm{ml} /$ $\mathrm{hr}$. The elution position of synthetic markers is indicated between the void volume ( $V_{\mathrm{o}}$ : albumin) and salt $\left(V_{\mathrm{NaCl}}\right)$ positions. $K_{\mathrm{av}}=V_{\mathrm{x}}-V_{\mathrm{v}} / V_{\text {salt }}-V_{\mathrm{o}}$. SS14 immunoreactivity is indicated by the solid line.

and markedly potentiated the high potassium-evoked release of SS14 without significantly altering the tissue content of the tetradecapeptide. The effect of cysteamine on the release of SS14 is calcium-dependent (Bakhit et al., 1983b), which indicates that it occurs by a specific release mechanism. In contrast, when the release of SS28(1-12)-LI was examined in the presence of cysteamine, no significant difference in the release of this peptide was observed when compared to the control group. Thus, the release of SS14 can be selectively enhanced without altering the release of SS28(1-12)-LI.

The immunohistochemical data complement and lend further support toward a differentiation between SS14 and SS28(1-12). The hypothalamic staining pattern with the antisera directed against SS28(1-12) (s320) was different than that directed against SS14 (s312). Since the distribution of staining with the s312 antisera does not always correlate with tissue levels of $\mathrm{SS} 14$ as detected by radioimmunoassay (Morrison et al., 1982, 1983), the staining pattern obtained with s312 should be interpreted with some caution. The apparent discrepancy between the immunohistochemistry and radioimmunoassay in the detection of SS14 should not, however, detract from the differential histochemical effects that were observed following cysteamine treatment. Staining of cell bodies and fibers with s312 was clearly diminished in the periventricular and ventral hypothalamic area following cysteamine treatment. The staining observed with ss9 also confirms the results obtained with s312. Since ss9 recognizes both SS28 and SS14, cysteamine pretreatment should result in reduced staining as a result of the depletion of SS14. The results presented in Figures 4 and 5 clearly demonstrate this expectation. Labeling of fibers was clearly diminished following cysteamine treatment. However, cell body labeling, although reduced, remained. These results with ss9 suggest that the antigenic material 


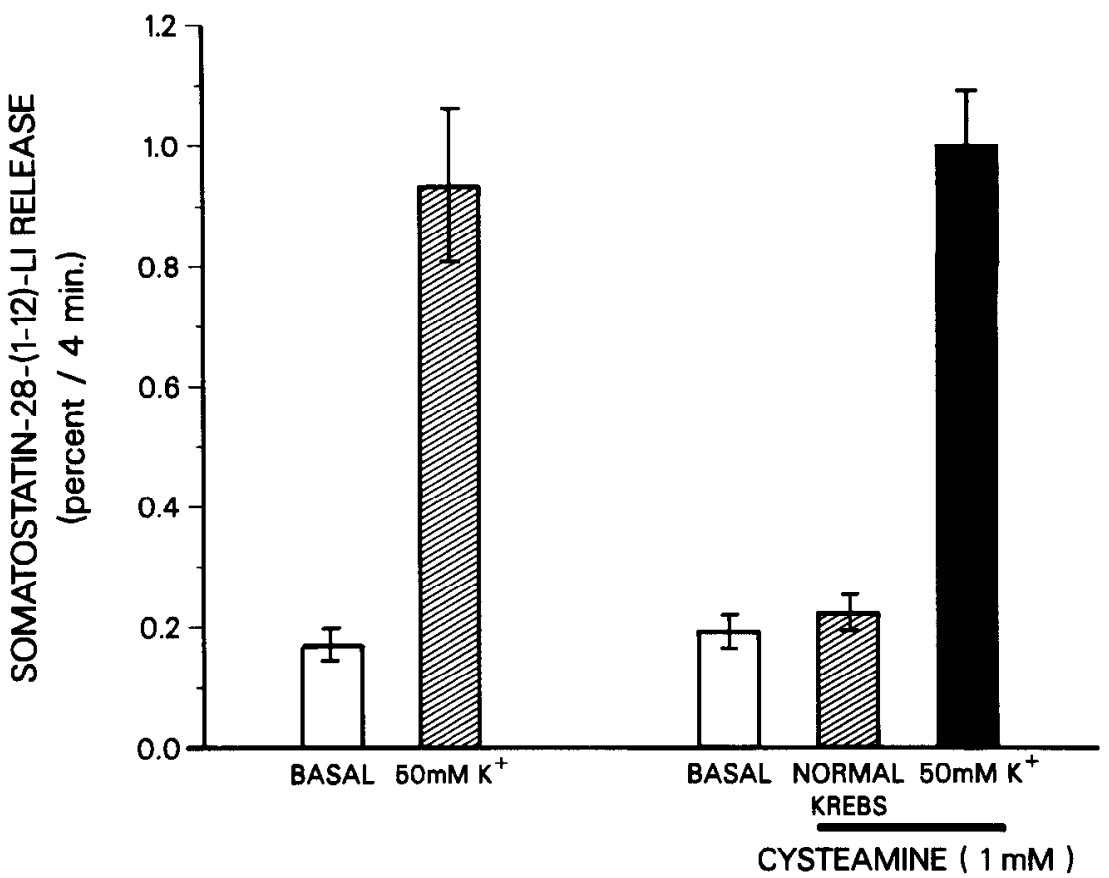

Figure 3. The effects of in vitro cysteamine ( $1 \mathrm{mM})$ on the spontaneous and potassium-evoked release of SS28(1-12) from rat hypothalamic slices in vitro. Results are expressed as percentage of tissue content measured in tissue slices at the end of the experiment. Values are mean \pm SEM of three separate experiments.

found in cell bodies is somewhat protected from the action of cysteamine. The staining with the s320 antiserum which recognizes SS28(1-12) was not appreciably changed following cysteamine treatment.

Given the above observations, several possibilities may exist regarding the storage of releasable SS14 and SS28(1-12) in synaptic terminals. SS14 and SS28(1-12) may be contained in the same synaptic vesicle or in separate vesicles in the same neuron. Alternatively, one or the other of these two somatostatin-related peptides might be predominant in a given synaptic terminal.

Based on the current understanding of vesicular storage and release of neurotransmitters, it is reasonable to assume a vesicular release mechanism for both $\mathrm{SS} 14$ and SS28(1-12); both peptides have been shown to be released in a calcium-dependent manner (Iversen et al., 1978; Bakhit et al., 1983a), and SS28(1-12) has been shown to be stored in mature secretory granules in the pancreas (Ravazzola et al., 1983). If SS14 and SS28(1-12) are contained in the same vesicle in similar or varying proportions, then one might expect cysteamine to enhance the release of both peptides. Cysteamine, however, enhances the release of SS14 only.

Alternatively, if SS14 and SS28(1-12) are contained in separate vesicles in the same synaptic terminal, it is conceivable that cysteamine selectively enhances the release of SS14. It should be noted that evidence for multiple neurotransmitters coexisting in the same neuron has been described (Hokfelt et al., 1980; Vincent et al., 1982). The release process in a synaptic terminal that contains multiple neurotransmitters has not, to our knowledge, been investigated. For instance, it is not known whether neurotransmitters coexisting in the same nerve terminal are released at the same time or whether selective release can occur at different frequencies of activation.

Another possibility that may explain our observations is that one of the somatostatin-related peptides, all derived from a common large precursor (Goodman et al., 1982; Shen et al., 1982), may predominate in a given synaptic terminal. Differential post-translational processing of the same precursor to produce different end products or a different ratio of the peptidic fragments may occur. Evidence supporting cell-specific processing of prosomatostatin can be drawn from studies done in the brain (Benoit et al., 1982a, b), pancreas (Benoit et al., 1980; Ravazzola et al., 1983), and gastrointestinal tract (Benoit et al., 1982c). For instance, different ratios of SS28, SS14, and SS28(1-12) were found in different regions of the brain (Rorstad et al., 1979; Benoit et al., 1982d) and peripheral nerves (Rasool et al., 1981; Reichlin, 1981). Furthermore, whereas SS14 and SS28(1-12) were predominant in the pancreas and hypothalamus (Benoit et al., 1980), SS28 was found to be the predominant somatostatin-related peptide in the intestinal mucosa (Patel et al., 1982). It should be noted that differential processing of another peptide precursor has been demonstrated for C-terminal fragments (Zakarian and Smyth 1979, 1982; Gramsch et al., 1980). A similar scheme based on immunohistochemical staining of $\gamma$ $\mathrm{MSH} / \beta$-endorphin has also been proposed (Bloom et al., 1980 ). It is conceivable that there are two peptidergic systems genetically coded to express preferentially one or the other of these putative somatostatin-related neurotransmitters. If that were the case, then cysteamine is acting on the neuronal system containing predominantly 

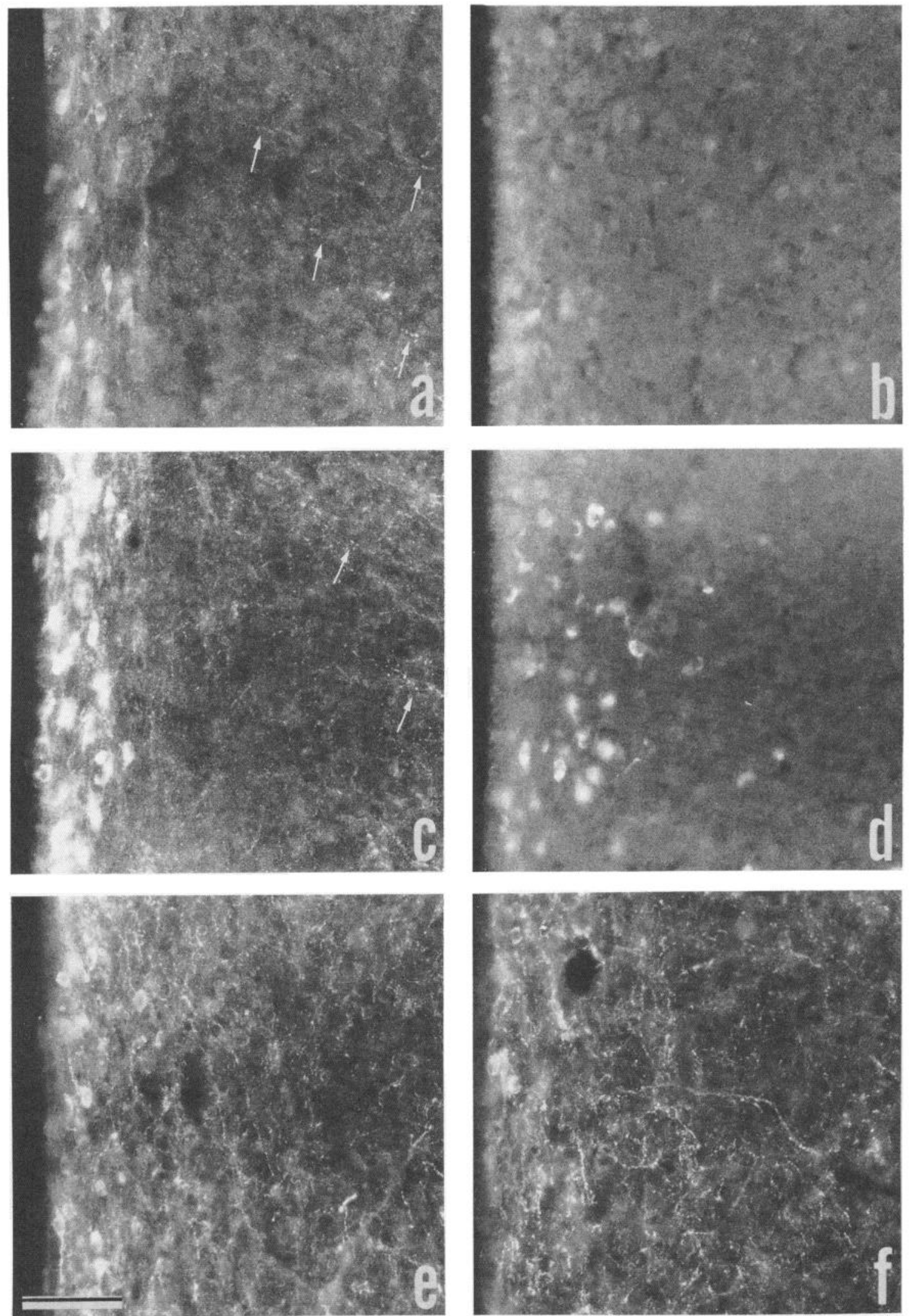

Figure 4. Fluorescent micrographs of somatostatin-like immunoreactive cell bodies and fibers in the rat periventricular hypothalamic area. The third ventricle appears along the left margin of each micrograph. Representive tissue from a normal rat and from a cysteamine-treated rat $(4 \mathrm{hr}$ after $300 \mathrm{mg} / \mathrm{kg}$, s.c.) are presented in the left and right columns, respectively. $a$ and $b$, Tissue incubated with antiserum that only recognizes somatostatin-14. Note that the labeling of cells and fine caliber fibers seen in normal tissue $(a)$ is absent following cysteamine treatment $(b) . c$ and $d$, Tissue incubated with antiserum that recognizes both somatostatin-14 and somatostatin-28. Cysteamine treatment reduced labeling of fibers, but cell body labeling was still apparent $(d) . e$ and $f$, Tissue incubated with antiserum that recognizes only somatostatin-28(1-12). Note that cysteamine treatment had little effect on either cell body or fiber labeling. Bar $=500 \mu \mathrm{m}$. 

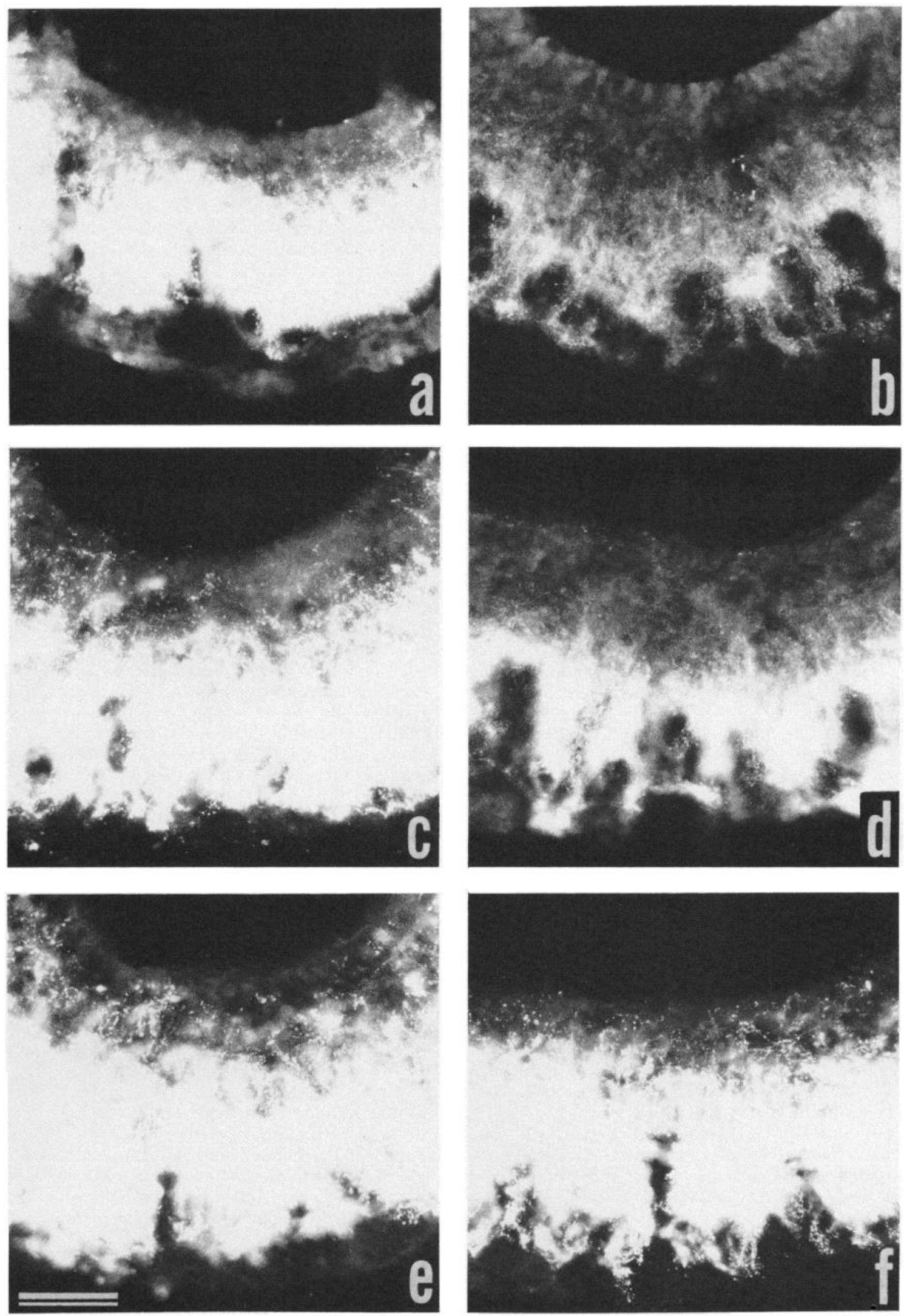

Figure 5. Fluorescent micrographs of somatostatin-like immunoreactive fibers in the rat median eminence. The third ventricle appears along the top margin of each micrograph. Representative tissue from a normal rat and from a cysteamine-treated rat (4 $\mathrm{hr}$ after $300 \mathrm{mg} / \mathrm{kg}$, s.c.) are presented in the left and right columns, respectively. $a$ and $b$, Tissue incubated with antisrum that only recognizes somatostatin-14. Note the reduced labeling of fibers following cysteamine treatment (versus $b$ ). $c$ and $d$, Tissue incubated with antiserum that recognizes both somatostatin-14 and somatostatin-28. Note the moderate reduction of labeling following cysteamine treatment $(c$ versus $d)$. $e$ and $f$, Tissue incubated with antiserum that recognizes only somatostatin-28(112). Note that cysteamine treatment had no effect on fiber labeling. Bar $=500 \mu \mathrm{m}$. 
SS14. In any case, the effects of cysteamine suggest the possibility of differential release.

The present experiments do not yet provide definitive evidence as to whether SS14 and SS28(1-12) are released from the same or different neurons. These results suggest, however, that in the rat hypothalamus selective release of SS14 and SS28(1-12) may occur under certain conditions.

\section{References}

Bakhit, C., R. Benoit, and F. E. Bloom (1983a) Release of somatostatin-28(1-12) from rat hypothalamus in vitro. $\mathrm{Na}$ ture 301: 524-526.

Bakhit, C., R. Benoit, and F. E. Bloom (1983b) Effects of cysteamine on pro-somatostatin related peptides. Regul. Pept. 6: 169-177.

Benoit, R. P. Bohlen, P. Brazeau, N. Ling, and R. Guillemin (1980) Isolation and characterization of rat pancreatic somatostatin. Endocrinology 107: 2127-2129.

Benoit, R., P. Bohlen, N. Ling, A. Briskin, F. Esch, P. Brazeau, S. -Y. Ying, and R. Guillemin (1982a) Presence of somatostatin-28(1-12) in hypothalamus and pancreas. Proc. Natl. Acad. Sci. U. S. A. 79: 917-921.

Benoit, R., N. Ling, B. Alford, and R. Guillemin (1982b) Seven peptides derived from pro-somatostatin in rat brain. Biochem. Biophys. Res. Commun. 107: 944-950.

Benoit, R., N. Ling, C. Bakhit, J. H. Morrison, B. Alford, and R. Guillemin (1982c) Somatostatin-28(1-12)-like immunoreactivity in the rat. Endocrinology 111: 2149-2151.

Benoit, R., J. H. Morrison, B. Alford, and C. Bakhit (1982d) Prosomatostatin derived peptides in rat tissue extracts. Endocrinology 110: A913.

Bloom, F. E., E. L. F. Battenberg, T. Shibasaki, R. Benoit, N. Ling, and R. Guillemin (1980) Localization of $\gamma$-melanocyte stimulating hormone $(\gamma \mathrm{MSH})$ immunoreactivity in rat brain and pituitary. Regul. Pept. 1: 205-222.

Brown, M. R., L. A. Fisher, P. E. Sawchenko, L. W. Swanson, and W. W. Vale (1983) Biological effects of cysteamine: Relationship to somatostatin depletion. Regul. Pept. 5: 163179.

Brownstein, A., A. Arimura, H. Sato, A. V. Schally, and J. S. Kizer (1975) The regional distribution of somatostatin in the rat brain. Endocrinology 96: 1456-1461.

Chesselet, M. -F., and T. O. Reisine (1983) Somatostatin regulates dopamine release in rat striatal slices and cat caudate nuclei. J. Neurosci. 3: 232-236.

Dodd, J, and J. S. Kelly (1978) Is somatostatin an excitatory transmitter in the hippocampus? Nature 273: 674-675.

Epelbaum J, P. Brazeau, D. Tsang, J. Brawer, and J. B. Martin (1977) Subcellular distribution of radioimmunoassayable somatostatin in rat brain. Brain Res. 126: 309-323.

Gamse, R., D. E. Vaccaro, G. Gamse, M. DiPace, T. O. Fox, and S. Leeman (1980) Release of immunoreactive somatostatin from hypothalamic cells in culture: Inhibition by $\gamma$ aminobutyric acid. Proc. Natl. Acad. Sci. U. S. A. 77: 55525556.

Glowinski, J., and L. L. Iversen (1966) Regional studies of catecholamines in the rat brain. J. Neurochem. 13: 655-669.

Goodman, R. H., J. W. Jacobs, P. C. Dee, and J. F. Habener (1982) Somatostatin- 28 encoded in a cloned cDNA obtained from a rat medullary thyroid carcinoma. J. Biol. Chem. 257: $1156-1159$.

Gothert, M. (1980) Somatostatin selectively inhibits noradrenaline release from hypothalamic neurons. Nature 288: 86-88.

Hokfelt, T., S. Efendic, O. Johansson, R. Luft, and A. Arimura (1974) Immunohistochemical localization of somatostatin (growth hormone release-inhibiting factor) in the guinea pig brain. Brain Res. 80: 165-169.

Hokfelt, T., O., Johansson, A. Ljungdahl, J. M. Lundberg, and M. Schultzberg (1980) Peptidergic neurons. Nature 284: 515521.

Iversen, L. L., S. D. Iversen, F. E. Bloom, C. Douglas, M. Brown, and W. Vale (1978) Calcium-dependent release of somatostatin and neurotensin from rat brain in vitro. Nature 273: $161-164$.

Kewley, C. F., R. P. Miller, M. C. Berman, and A. V. Schally (1981) Depolarization and ionophore-induced release of octacosa somatostatin from stalk median eminence synaptosomes. Science 213: 913-915.

Kobayashi, R. M., M. Brown, and W. Vale (1977) Regional distribution of neurotensin and somatostatin in rat brain. Brain Res. 126: 584-588.

Morrison, J. H., R. Benoit, P. J. Magistretti, N. Ling, and F. E. Bloom (1982) Immunohistochemical distribution of prosomatostatin related peptides in hippocampus. Neurosci. Lett. 34: 137-142.

Morrison, J. H., R. Benoit, P. J. Magistretti, and F. E. Bloom (1983) Immunohistochemical distribution of pro-somatostatin related peptides in cerebral cortex. Brain Res. 262: 344351.

Olpe, H. -R., V. J. Balcar, H. Bittiger, H. Rink, and P. Sieber (1980) Cenral actions of somatostatin. Eur. J. Pharmacol. 63: $127-133$.

Palkovits, M., M. J. Brownstein, L. E. Eiden, M. C. Beinfeld, J. Russell, A. Arimura, and S. Szabo (1982) Selective depletion of somatostatin in rat brain by cysteamine. Brain Res. 240: 178-180.

Patel, Y. C., T. Wheatley, and C. Ning (1982) Multiple forms of immunoreactive somatostatin: Comparison of distribution in neural and nonneural tissues and portal plasma of the rat. Endocrinology 109: 1943-1949.

Pittman, Q. J., and G. R. Siggins (1981) Somatostatin hyperpolarizes hippocampal pyramidal cells in vitro. Brain Res. 221: 402-408.

Rasool, C. G., A. L. Schwartz, J. A. Bollinger, S. Reichlin, and W. G. Bradley (1981) Immunoreactive somatostatin distribution and axoplasmic transport in rat peripheral nerve. Endocrinology 108: 996-1001.

Ravazzola, M., R. Benoit, N. Ling, R. Guillemin, and L. Orci (1983) Immunocytochemical localization of prosomatostatin fragments in maturing and mature secretory granules of pancreatic and gastrointestinal D cells. Proc. Natl. Acad. Sci. U. S. A. 80: 215-218.

Reichlin, S. (1981) Systems for the study of regulation of neuropeptide secretion. In Neurosecretion and Brain Peptides, J. B. Martin, S. Reichlin, and K. L. Bick, eds., pp. 5735987, Raven Press, New York.

Reubi, J. -C., M. Perrin, J. Rivier, and W. Vale (1981) High affinity binding sites for a somatostatin-28 analog in rat brain. Life Sci. 28: 2191-2198.

Rorstad, O. P., J. Epelbaum, P. Brazeau, and J. B. Martin (1979) Chromatographic and biological properties of immunoreactive somatostatin in hypothalamic and extrahypothalamic brain regions of the rat. Endocrinology 105: 10831092.

Sagar, S. M., D. Landry, W. M. Millard, T. M. Badger, M. A. Arnold, and J. B. Martin (1982) Depletion of somatostatinlike immunorcactivity in the rat central nervous systems by cysteamine. J. Neurosci. 2: 225-231.

Shen, L. -P., R. L. Pictet, and W. Rutter (1982) Human somatostatin I: Sequence of the cDNA. Proc. Natl. Acad. Sci. U. S. A. 79: 4575-4579.

Srikant, C. B., and Y. C. Patel (1981) Receptor binding of somatostatin-28 is tissue specific. Nature 294: 259-260. 
Szabo, S., and S. Reichlin (1981) Somatostatin in rat tissue is depleted by cysteamine administration. Endocrinology 109: 2255-2257.

Tanaka, S., and A. Tsujimoto (1981) Somatostatin facilitates the serotonin release from rat cerebral cortex, hippocampus and hypothalamus slices. Brain Res. 208: 219-222.

Tapia-Arancibia, L., J. Epelbaum, A. Enjalbert, and C. Kordon (1981) Somatostatin binding sites in various structures of the rat brain. Eur. J. Pharmacol. 71: 523-525.

Vincent, S. R., O. Johansson, T. Hokfelt, B. Meyerson, C. Sachs, R. P. Elde, L. Terenius, and J. Kimmel (1982) Neuropeptide coexistence in human cortical neurons. Nature 298: 65-67.

Zakarian, S., and D. Smyth (1982) $\beta$-Endorphin is processed differently in specific regions of rat pituitary and brain. Nature 296: 250-252. 